\title{
Molecular Editing of Flavins for Catalysis
}

\author{
Andreas Rehpenn $\diamond$ \\ Alexandra Walter ${ }^{\diamond}$ \\ Golo Storch* (1)
}

Department Chemie, Technische Universität München, Lichtenbergstr. 4, 85747 Garching, Germany

$\diamond$ These authors contributed equally golo.storch@tum.de

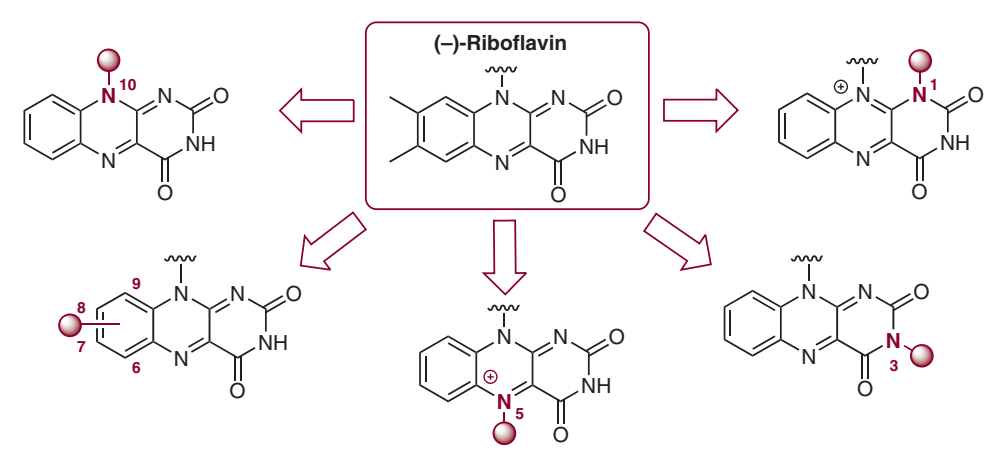

Improved Flavin Catalysts

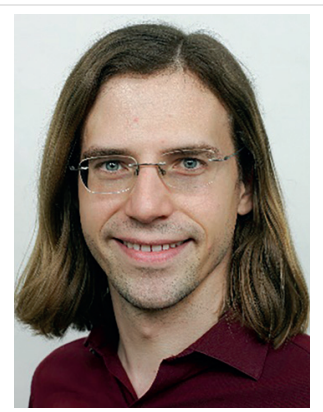

Abstract The diverse activity of flavoenzymes in organic transformations has fascinated researchers for a long time. However, when applied outside an enzyme environment, the isolated flavin cofactor only shows largely reduced activity. This highlights the importance of embedding the reactive isoalloxazine core of flavins in defined surroundings. The latter include crucial non-covalent interactions with amino acid side chains or backbone as well as controlled access to reactants such as molecular oxygen. Nevertheless, molecular flavins are increasingly applied in the organic laboratory as valuable organocatalysts. Chemical modification of the parent isoalloxazine structure is of particular interest in this context in order to achieve reactivity and selectivity in transformations, which are so far only known with flavoenzymes or even unprecedented. This review aims to give a systematic overview of the reported designed flavin catalysts and highlights the impact of each structural alteration. It is intended to serve as a source of information when comparing the performance of known catalysts, but also when designing new flavins. Over the last few decades, molecular flavin catalysis has emerged from proof-of-concept reactions to increasingly sophisticated transformations. This stimulates anticipating new flavin catalyst designs for solving contemporary challenges in organic synthesis.

Introduction

N1-Modification

N3-Modification

N5-Modification

C6-C9-Modification

N10-Modification

Conclusion

Key words flavin catalysis, organic synthesis, biomimetic chemistry, organocatalysis

\section{Introduction}

Enzymes which rely on a flavin cofactor (flavoenzymes) have been studied in detail and structural as well as mecha-
Golo Storch obtained his B.Sc. and M.Sc. in chemistry at Heidelberg University with a research stay at the Laboratoire de Chimie de Coordination (LCC) du CNRS in Toulouse. Subsequently, he joined the group of Prof. Oliver Trapp at Heidelberg University and obtained his Ph.D. in 2016 with a thesis in the field of stereodynamic ligands and their application in self-amplifying catalysis. He then moved to Yale University and explored quinone redox-interconversion as well as peptide ligands for site-selective catalysis as a DFG research fellow with Prof. Scott Miller. Since 2019 he is junior research group leader at TU Munich funded by a Liebig Fellowship of the Fonds der Chemischen Industrie (FCI). His current research interests include all aspects of designing molecular flavin catalysts for applications in organic synthesis.

nistic insights are documented. ${ }^{1}$ The diverse areas of catalytic activity have been of particular interest and the specific roles of flavoenzymes in many chemical transformations have been addressed systematically. ${ }^{2}$ The cofactor itself is either covalently linked to the enzyme backbone or held in position by defined non-covalent interactions. ${ }^{3}$ Common to all flavoenzymes is a reactive isoalloxazine heterocycle, which is usually part of the flavin adenine dinucleotide (FAD) cofactor 1 (Figure 1A). The quinoid structure of isoalloxazine is a strong oxidant which also is its primary reactivity towards substrate molecules. A second typical reactivity of flavins is substrate oxygenation, which is made possible by activation of molecular oxygen from air followed by formation of hydroperoxide intermediate 2 (Figure $1 \mathrm{~B}) .^{4} \mathrm{~A}$ fascinating aspect in flavoenzyme mechanisms is the variety of oxidation states in which the cofactor is 
active and possesses individual reactivity characteristics. The three most common oxidation states include the fully oxidized quinoid state, the one-electron reduced semiquinone, and the fully reduced hydroquinone state (Figure 1C). All of these properties taken together explain why the analogous cofactor is capable of mediating completely unrelated transformations in flavoenzymes depending on a reducing or oxidizing surrounding as well as additional parameters such as availability of molecular oxygen.

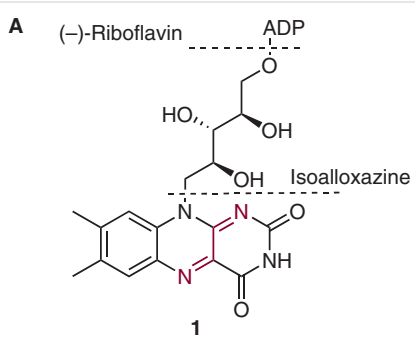

Flavin Adenine Dinucleotide (FAD)

c<smiles>Cc1cc2nc3c(=O)[nH]c(=O)nc-3n(C)c2cc1C</smiles><smiles>Cc1cc2c(cc1C)N(C#N)C1=NC(=O)NC(=O)C1N2</smiles>

Semiquinonid

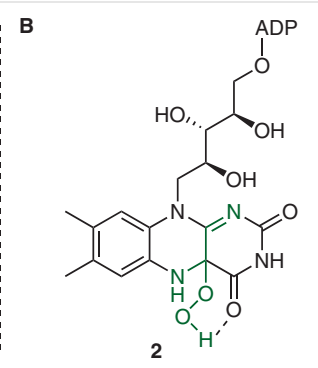

inium salts. However, these compounds are still regarded as alterations of the parent isoalloxazine and included in this review.

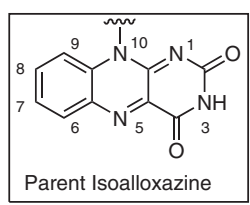<smiles></smiles><smiles>Cn1c2nc(=O)n(O)c(=O)c-2nc2ccccc21</smiles><smiles></smiles><smiles></smiles>

C6-C9-Modification

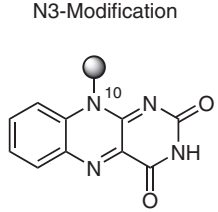

N10-Modification

Figure 2 The structure of isoalloxazine including the numbering scheme is shown in the top left box. Five positions of flavin alterations are discussed within this review and are highlighted in representative structures with grey spheres.

Throughout this review many flavin catalysts are modified at more than one of the above-mentioned positions. In these cases, they are not mentioned twice, but are assigned to the substitution position which impacts reactivity or selectivity most.

Figure 1 Characteristic features of the flavin cofactor. (A) Structure of flavin adenine dinucleotide. (B) Covalent hydroperoxide intermediate which is formed upon activation of molecular oxygen. (C) The three most common oxidation states of the isoalloxazine core. ADP: adenosine diphosphate.

Without an enzyme surrounding, the isolated flavin cofactor loses a large part of its activity, which has been demonstrated by direct comparison to flavoenzymes. ${ }^{5}$ This observation underlines the crucial importance of the proximal surroundings of the isoalloxazine core and the involvement of non-covalent interactions in efficient reaction processes. However, in spite of the reduced activity, the isolated cofactor, especially commercially available (-)-riboflavin, has been used in the organic laboratory with growing interest and flavin catalysis has been recognized as a useful tool in synthesis. ${ }^{6}$ The fact that flavins can also be photoexcited has been of additional interest and especially the strongly oxidizing properties after irradiation have found wide application in synthetic chemistry. ${ }^{7}$

It is the aim of this review to give an overview of how alterations of the isoalloxazine core have been utilized to design and apply molecular flavin catalysts for individual catalytic reactions. Therefore, methods using the unmodified, natural (-)-riboflavin as catalyst will not be discussed. Five different positions of alteration have been identified and will be discussed in detail: N1-, N3-, N5-, C6-C9-, and N10-modification (Figure 2). Upon N1-modification, some of the resulting flavins are formally alloxazines or alloxaz-

\section{N1-Modification}

Unlike in flavoenzymes, isolated (-)-riboflavin does not readily form covalent adducts with nucleophiles such as hydrogen peroxide or amines in solution. In order to increase the molecular reactivity of flavin, the Sayre group reported a straightforward synthesis of N1-N10-bridged flavinium salt 3 in $2001 .^{8}$ This compound was found to be a stronger oxidant compared to the parent isoalloxazine and could also be reduced reversibly. Interestingly, covalent adducts with nucleophiles are not formed in the C4a-position (which is known for flavin hydroperoxides in enzymes), but rather in the $\mathrm{C} 10 \mathrm{a}$-position. This is exemplified by the reaction with hydrogen peroxide resulting in adduct $\mathbf{4}$ (Scheme 1).
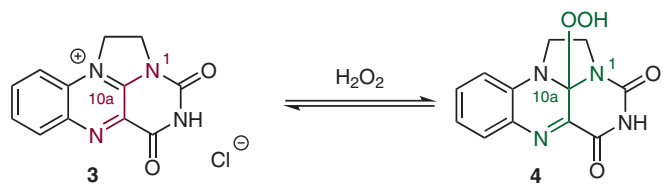

Scheme 1 Molecular structure of a N1-N10-bridged flavinium salt and its reaction with a hydrogen peroxide nucleophile

In 2010, the Carbery group built upon these studies and reported the use of this class of flavinium catalysts for the oxidation of aryl and alkyl thioethers with hydrogen peroxide (Scheme 2). ${ }^{9}$ They observed that especially electron- 
withdrawing substituents, like in chloro derivative $\mathbf{5}$, lead to high catalytic activity. This reaction has been found to be very robust and also allows catalytic application in mixtures of water and organic solvent. ${ }^{10}$

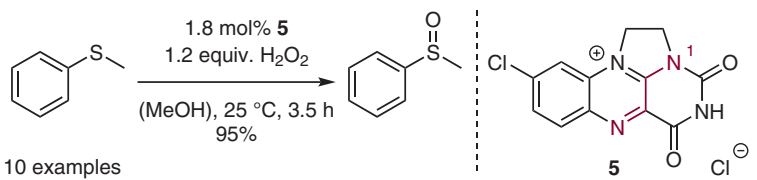

10 examples

Scheme 2 Catalytic activity of flavinium salt $\mathbf{5}$ in the activation of hydrogen peroxide and oxidation of a series of thioether substrates

While thioether oxidation proceeds by nucleophilic attack on flavin hydroperoxide intermediate $\mathbf{4}$, the latter was also found to act as a nucleophile in combination with suitable substrates. Electron-deficient flavinium salt 6 was reported to mediate the oxidation of aldehydes to the corresponding carboxylic acids efficiently (Scheme 3$).{ }^{11}$ Similar nucleophilic reactivity of the hydroperoxide intermediate was used in Baeyer-Villiger oxidation with N1-N10bridged flavins. ${ }^{12}$
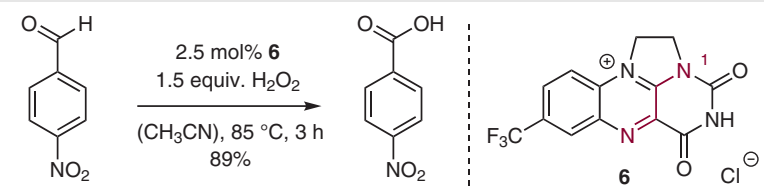

23 examples

Scheme 3 Flavinium catalyst 6 is also active in oxidation of aldehyde substrates to carboxylic acids

The efficiency of the synthetic route towards flavinium catalysts of the N1-N10-bridged type also stimulated the exploration of chiral versions for enantioselective applications. The Cibulka group reported a variety of chiral flavinium salts 7, which are derived from enantiopure amino acids as the sole source of chiral information (Figure $3 \mathrm{~A}$ ). ${ }^{13}$ Derivative $\mathbf{7 c}$ showed high facial selectivity in the reaction with hydrogen peroxide, yielding the hydroperoxide adduct in $>95: 5$ diastereoselectivity. Yamamoto and co-workers expanded the series of chiral variants by flavinium salt 8 , which has two substituents at the N1-N10 bridge (Figure 3B). ${ }^{14}$ This catalyst was applied as an ion pair with chinchona alkaloids and enabled the enantioselective Baeyer-Villiger oxidation of cyclobutanone substrates.
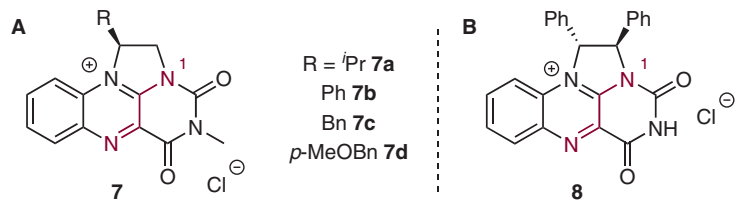

Figure 3 Chiral variants of N1-N10-bridged flavinium catalysts; both types were applied in stereoselective oxidation reactions

The reduced form of N1-N10-bridged flavinium catalysts, hydroquinoid compound $\mathbf{9}$, also reacts with molecular oxygen in analogy to parent (-)-riboflavin. In unmodified flavins, this reaction results in initial formation of hydroperoxides followed by fast and irreversible hydrogen peroxide elimination. However, reaction of $\mathbf{9}$ with molecular oxygen results in hydroperoxide 4 , which is the active intermediate in all previously described catalytic cycles using hydrogen peroxide (Scheme 4).

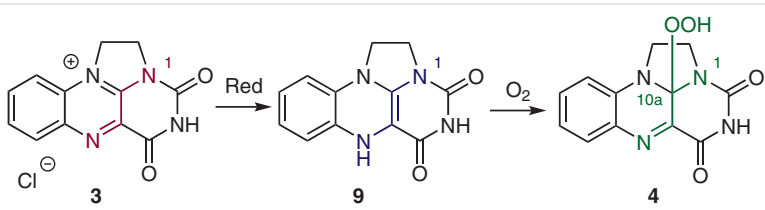

Scheme 4 Activation of molecular oxygen occurs with reduced flavin 9 and results in formation of $\mathrm{C} 10 \mathrm{a}$-hydroperoxide; Red: reduction

When eliminating hydrogen peroxide, hydroperoxide 4 is converted into the oxidized flavinium catalyst $\mathbf{3}$ (cf. Scheme 1). This strategy for oxidation of the reduced flavin catalyst intermediate $\mathbf{9}$ with molecular oxygen has been used in various ways to close the catalytic cycle of oxidation reactions. N1-N10-Bridged flavinium salts were found to be exceptionally stable and well suited in this context. In 2011, the Carbery group used catalyst 6 for the oxidation of hydrazine to diazene $\left(\mathrm{N}_{2} \mathrm{H}_{2}\right)$. The latter subsequently served as a reductant for $\mathrm{C}=\mathrm{C}$ bonds. ${ }^{15}$ Re-oxidation of the reduced flavin intermediate was achieved by molecular oxygen. The same catalyst 6 was also successfully applied in the re-oxidation of $\mathrm{NAD}(\mathrm{P}) \mathrm{H}$ to $\mathrm{NAD}(\mathrm{P})^{+}$under aerobic conditions, which made dehydrogenase activity possible with air as terminal oxidant. ${ }^{16}$ Both N1-N10-bridged flavinium salts and the corresponding hydroperoxides oxidize iodide to iodine and the catalytic couple $\mathbf{1 0}+\mathrm{I}_{2}$ (or $\mathrm{I}^{-}$) was found to act synergistically with iodine being constantly regenerated by the flavin catalyst and molecular oxygen. ${ }^{17}$ The concept was applied in the transformation of tosyl hydrazones to 1,2,3-thiadiazoles (Scheme 5).

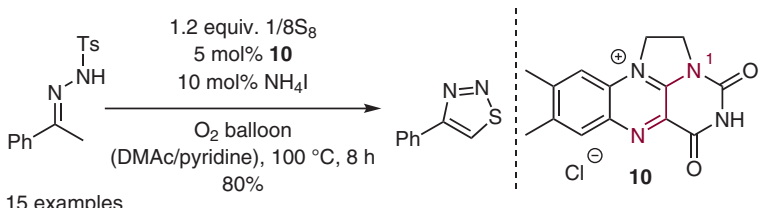

15 examples

Scheme 5 Flavinium catalyst $\mathbf{1 0}$ constantly re-cycles iodide to iodine under aerobic conditions. The catalyst couple $\mathbf{1 0}+\mathrm{NH}_{4} \mathrm{I}$ was applied in 1,2,3-thiadiazole formation. DMAc: $N, N$-dimethylacetamide.

Foss and co-workers showed in 2020 that re-oxidation of flavinium catalyst $\mathbf{3}$ with $\mathrm{O}_{2}$ closes the catalytic cycle of converting nitromethane into $\mathrm{NO}_{2}^{-} .^{18}$ In a separate cycle, the latter subsequently oxidizes TEMPOH to TEMPO', which 


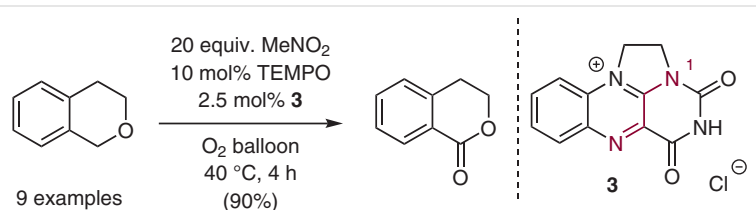

Scheme 6 Benzylic oxidation mediated by flavinium catalyst 3 in combination with TEMPO

led to efficient $\mathrm{CH}$-oxygenation of chromane substrates (Scheme 6).

Contrary to oxygen nucleophiles, phosphorous nucleophiles react with N1-N10-bridged flavinium catalysts at N5- and not at the C10a-position. These observations were used by the Cibulka group in 2019 in order to replace stoichiometric diethyl azodicarboxylate (DEAD) in Mitsunobu esterification reactions. ${ }^{19}$ Addition of triphenylphosphine to flavinium catalyst $\mathbf{1 1}$ results in covalent intermediate $\mathbf{1 2}$, which has been fully characterized (Scheme 7). Attack of an alcohol substrate on the phosphorus atom of the intermediate yields an oxyphosphonium cation (the reaction then proceeds in analogy to the standard Mitsunobu esterification) concomitant to release of the reduced flavin species; the latter is re-oxidized with molecular oxygen. Under these reaction conditions, no reactivity was observed with neutral, N3-methylated (-)-riboflavin tetraacetate.

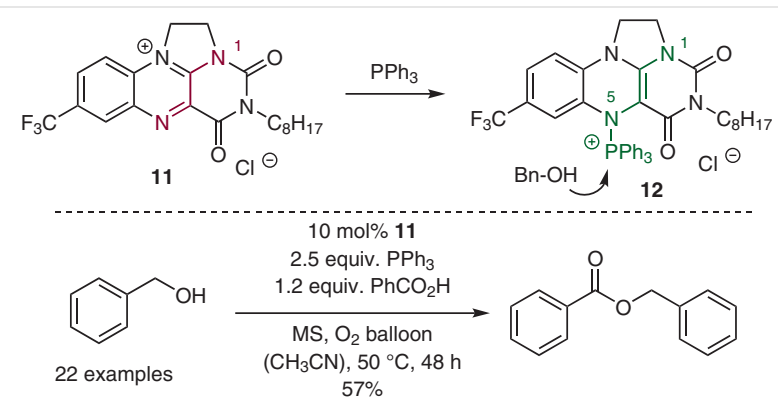

Scheme 7 Flavinium-catalyzed Mitsunobu esterification which does not require an azodicarboxylate for activation of triphenylphosphine; MS: molecular sieves

N1-N10-Bridged flavinium salts show characteristic absorption features in the visible spectrum around $\lambda_{\max } \approx 400 \mathrm{~nm}$ and also show fluorescence at $\lambda_{\mathrm{fl}} \approx 470 \mathrm{~nm}$. The Cibulka group successfully used irradiation with visible light to increase the redox potential of $\mathbf{1 1}$ from $E=+0.01 \mathrm{~V}$ (vs. saturated calomel electrode (SCE)) in the ground state to $E=+2.67 \mathrm{~V}$ (vs. SCE) in the excited state. ${ }^{20}$ Under these reaction conditions, they could achieve even very challenging oxidations, such as conversion of $p$-(trifluoromethyl)toluene $\left(E_{\text {OX }}=+2.61 \mathrm{~V}\right.$ (vs. SCE)) into the corresponding benzoic acid derivative (Scheme 8). The methodology has since been expanded to oxidations of benzylic positions and alcohols. ${ }^{21}$

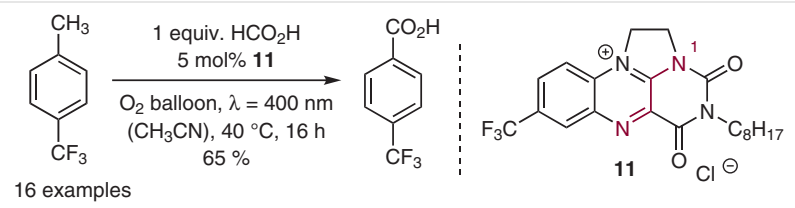

Scheme 8 Strongly oxidizing flavinium catalysts in the excited state for challenging oxidations yielding carboxylic acids

A detailed subsequent spectroscopic study revealed that contrary to the reactions in the dark, covalent hydroperoxide binding occurs at the C4a-position with formation of $\mathbf{1 3}$ when conducting the reactions with catalyst 11 photochemically (Scheme 9). ${ }^{22}$ This observation was rationalized based on a N5-blocking effect after initial proton-coupled electron transfer (PCET), which results in N5-protonation.

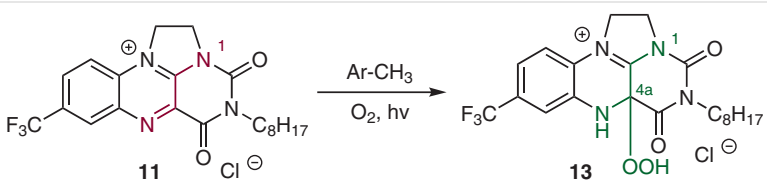

Scheme 9 Evidence for C4a-hydroperoxide formation when conducting substrate oxidation under irradiation was obtained by using photodissociation spectroscopy. In the depicted reaction, benzylic oxidation of the $\mathrm{Ar}-\mathrm{CH}_{3}$ substrate first generates a reduced flavin semiquinone. The latter reacts with $\mathrm{HOO}^{*}$ to give hydroperoxide $\mathbf{1 3}$.

Flavins which contain a substituent in the N1-position but are not substituted in the N10-position formally belong to the class of alloxazines. These compounds were found to be especially suitable as triplet sensitizers due to their significantly higher triplet energy when compared to isoalloxazines. In 2015, the Cibulka group reported flavin 14 as a competent photocatalyst for the [2+2]-cycloaddition of diene 15 (Scheme 10). ${ }^{23}$ No product formation was observed with (-)-riboflavin. This reactivity has also been observed with immobilized flavin catalysts ${ }^{24}$ and an expanded substrate scope. ${ }^{25}$

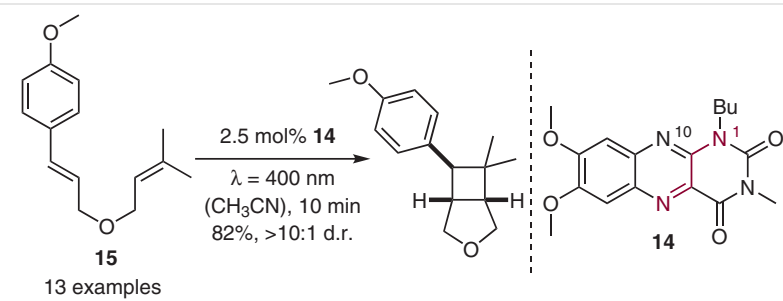

Scheme 10 Alloxazine catalyst $\mathbf{1 4}$ acts as sensitizer in the photocycloaddition of diene $\mathbf{1 5}$

\section{N3-Modification}

The N3-position of flavins is easily deprotonated and therefore the most straightforward choice for functionalization with electrophiles such as alkyl halides. Alkyl substitu- 
ents at the N3-position are the most common way to modulate the solubility of the flavin catalyst in organic media and these modifications will not be discussed here. Alkylation of the N3-position does not significantly alter the absorption and fluorescence spectra of flavin catalysts but has been found to increase photostability when comparing tetraacetylated (-)-riboflavin with and without N3-methylation. ${ }^{26}$ Redox properties are also only slightly changed due to the missing binding site for hydrogen bonding interaction. ${ }^{27}$ Therefore, significant changes in flavin catalytic activity upon modification of the N3-position rely on attaching substituents with additional functions that work in concert with the isoalloxazine. In 2004, Cibulka, König, and Vasold reported flavin 16, which was decorated with a Lewis acid binding site for substrate localization in proximity to the quinoid active site (Figure 4A). ${ }^{28}$ The zinc(II)-flavin conjugate showed 30 times higher quantum yields for photocatalytic oxidation of alcohol substrates when compared to flavins lacking the modification. Substitution of the N3-position also served as a strategy for immobilization of flavins by polymerization. Gilmour, Ravoo, and co-workers demonstrated the high catalytic activity of silica-supported flavin 17 (Figure $4 \mathrm{~B}$ ) in the $E$ to $Z$ isomerization of olefin substrates. ${ }^{29}$ Related strategies have also been used to immobilize flavin catalysts on gold nanoparticles ${ }^{30}$ as well as mesoporous silica. ${ }^{31}$

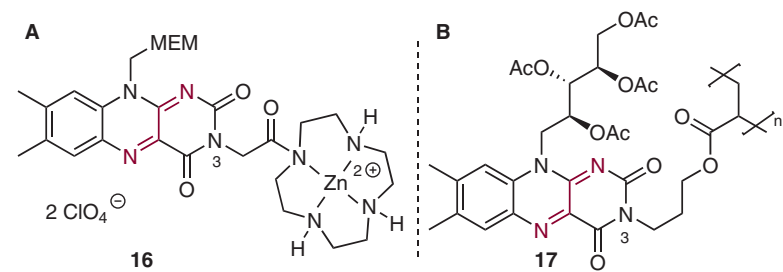

Figure 4 Modifications of the N3-position which significantly enhance catalytic activity (A) or allow for immobilization of flavins (B); MEM:

2-methoxyethoxymethyl

The Imada group reported flavin catalyst 18 with a peptide substituent at the N3-position (Figure 5A). ${ }^{32}$ They screened several turn sequences with the intention of facilitating the side chains of the peptide in reaching the reactive quinoid center and intermediate hydroperoxide. They identified $\mathbf{1 8}$ as the optimal catalyst for transformations with flavin hydroperoxides, which usually require substitution of either the N1- or N5-position. This observation was rationalized as a result of the carboxylic acid functionality in the aspartic acid (Asp) side chain. The latter was suggested to form stabilizing non-covalent hydrogen bonds to the flavin hydroperoxide intermediate (Figure 5B) thereby increasing its stability. Conjugate $\mathbf{1 8}$ was applied in BaeyerVilliger reactions and thioether oxidations, which are both not possible with (-)-riboflavin or simple isoalloxazines.

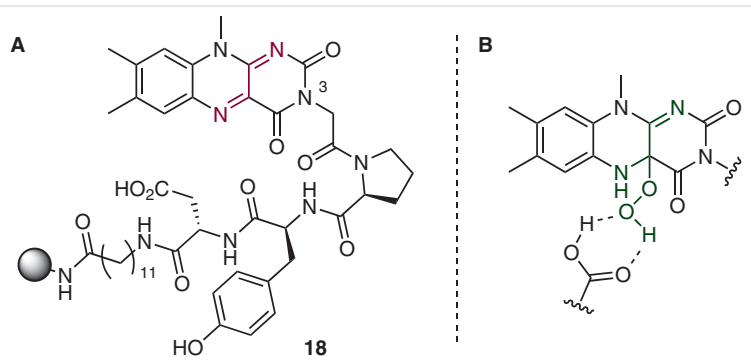

Figure 5 The peptide-flavin conjugate (A) was prepared by solid-phase synthesis on an amino-functionalized polystyrene resin, which is depicted as a grey sphere. Flavin $\mathbf{1 8}$ was then applied as a polymer-supported catalyst. The binding mode of the aspartic acid side chain to the hydroperoxide involves two hydrogen bonds (B).

\section{N5-Modification}

In 1976, the Bruice group reported that N5-alkylated flavinium salt 19, unlike (-)-riboflavin, reacts with hydrogen peroxide and forms a covalent adduct at the C4a-position (Scheme 11). ${ }^{33}$ This type of adduct formation and the reactivity of hydroperoxide $\mathbf{2 0}$ was thoroughly studied since it is an intermediate in many flavoenzyme-catalyzed oxygenation reactions. ${ }^{34}$ Alkylation at the N5-position is straightforward starting from the isoalloxazine and is typically achieved by reduction to the hydroquinoid state followed by reductive amination with a suitable aldehyde. ${ }^{35}$ Typically, acetaldehyde is used and, therefore, N5-ethyl catalysts are most common. Alternatively, the corresponding C4a-hydroxy analogues, stemming from addition of a molecule of water, ${ }^{36}$ can also be applied as pre-catalysts, which are activated by acid and elimination of water. ${ }^{37}$ Absorption and emission properties of N5-alkylated flavinium salts are similar to those of the parent isoalloxazines yet bathochromically shifted. ${ }^{38}$

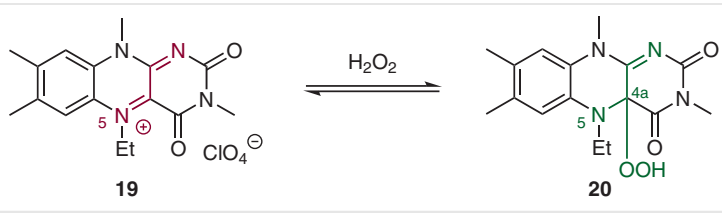

Scheme 11 Alkylation of the flavin N5-position results in flavinium salts. Ethylated catalyst 19 reacts with hydrogen peroxide and forms the corresponding hydroperoxide intermediate $\mathbf{2 0}$.

In the context of studies towards elucidating flavoenzyme reactivity, early reports by the Bruice group in 1980 revealed that hydroperoxide $\mathbf{2 0}$ efficiently mediates the oxidation of amine substrates. ${ }^{39}$ Building on these observations, Murahashi and co-workers achieved a catalytic method and they showed that a variety of thioethers and secondary amines are oxidized by hydrogen peroxide in the presence of $\mathbf{1 9}$ to the corresponding nitrones, sulfoxides, or sulfones depending on the substrate and reaction condi- 
tions (Scheme 12). ${ }^{40}$ They noted, that hydroperoxide $\mathbf{2 0}$ had a $10^{4}$ times higher catalytic activity compared to hydrogen peroxide.

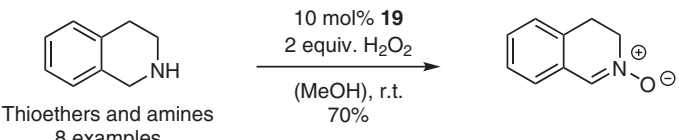

Scheme 12 Application of N5-alkylated flavinium catalyst 19 in oxygenation reactions with hydrogen peroxide as oxidant

The significant rate acceleration of N5-alkylated flavinium salts in heteroatom oxidations with hydrogen peroxide has been used in several variants ${ }^{41}$ including micellar systems $^{42}$ and polymer-bound ${ }^{43}$ flavinium catalysts. The general concept of hydrogen peroxide activation with flavinium catalysts of the 19-type was soon expanded to other reactions, in all of which (-)-riboflavin was not an active catalyst. In analogy to C10a-hydroperoxide 4, Furstoss and co-workers demonstrated in 1996 that C4a-hydroperoxide $\mathbf{2 0}$ also acts as a nucleophile and converts cyclobutanones in Baeyer-Villiger reactions. ${ }^{44}$

In analogy to reduced N1-substituted flavin 9, the reduced counterpart $\mathbf{2 1}$ also reacts with molecular oxygen resulting in hydroperoxide $\mathbf{2 0}$ (Scheme 13). This opens up the possibility to replace hydrogen peroxide with oxygen from air if a suitable reductant is used for converting flavinium salt 19 into the hydroquinoid state.

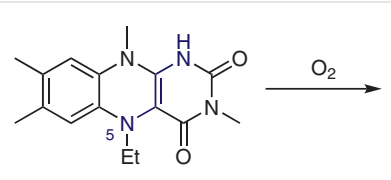

21

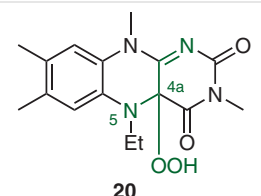

20
Scheme 13 The reaction of reduced N5-alkylated flavins with molecular oxygen as an alternative way to generate hydroperoxide $\mathbf{2 0}$

In 2003, Murahashi, Imada, and co-workers demonstrated that hydrazine hydrate serves as a competent reductant for this purpose. ${ }^{45}$ They showed that under these reducing conditions, flavinium salt $\mathbf{1 9}$ catalyzes the oxidation of thioether and amine substrates with molecular oxygen as the terminal oxidant (Scheme 14). This strategy for replacing hydrogen peroxide in oxidations was found to be broadly applicable and was subsequently used in a variety of heteroatom oxidations. ${ }^{46}$ In addition to hydrazine hydrate, oth-

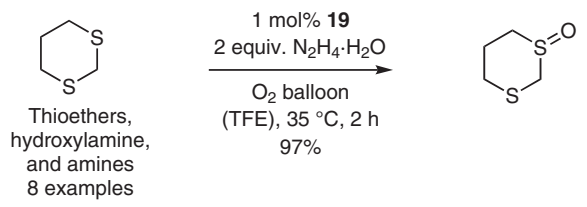

Scheme 14 Heteroatom oxidation reactions mediated by N5-ethylated flavinium catalyst 19; molecular oxygen serves as terminal oxidant er reducing agents including formic acid ${ }^{47}$ and ascorbic acid $^{48}$ were found to be also suitable in electrophilic oxidation reactions with N5-alkylated flavinium catalysts.

Yet another analogy of N1-substituted flavinium catalyst $\mathbf{3}$ and N5-substituted analogue $\mathbf{1 9}$ is their ability to form diazene from hydrazine, which then allows reduction of $\mathrm{C}=\mathrm{C}$ bonds (Scheme 15). ${ }^{49}$ Reaction of the reduced flavin species with molecular oxygen closes the catalytic cycle with hydrogen peroxide being released. The methodology was successfully applied to a variety of olefin substrates. ${ }^{50}$

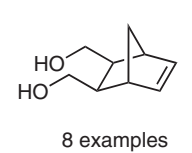

8 examples

$$
\begin{gathered}
\stackrel{1.0 \text { mol\% } 19}{1.2 \text { equiv. } \mathrm{N}_{2} \mathrm{H}_{4} \cdot \mathrm{H}_{2} \mathrm{O}} \\
\stackrel{1 \text { atm O }}{\longrightarrow}
\end{gathered}
$$$$
96 \%
$$

Scheme 15 Flavinium catalyst 19 serves as a source of diazene upon oxidation of hydrazine. The reduced flavin species is then re-oxidized by molecular oxygen.

The method of replacing hydrogen peroxide with molecular oxygen was also successfully expanded to transformations in which the flavin hydroperoxide acts as a nucleophile. In this context, zinc was found to be an ideal reducing agent in Baeyer-Villiger reactions using flavinium catalyst 22, which is derived from (-)-riboflavin (Scheme 16). ${ }^{51} \mathrm{Re}-$ oxidation of reduced N5-substituted flavinium catalysts with molecular oxygen has since been broadly applied including iodine-mediated reactions, ${ }^{52}$ catalytic water oxidation, ${ }^{53}$ and catalytic oxygenation of methylrhenium trioxide (MTO). ${ }^{54}$

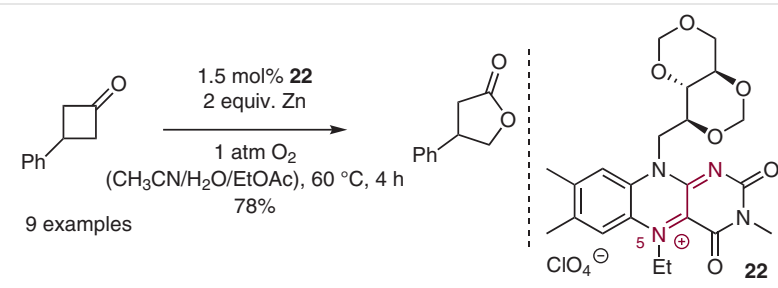

Scheme 16 Metallic zinc serves as competent reductant in BaeyerVilliger oxidation of cyclobutanone substrates with molecular oxygen as terminal oxidant

A particularly active class of flavinium catalysts stems from combined N1- and N5-substitution without a substituent in the N10-position. Formally, these compounds are N5-substituted alloxazines. In 1998, the Bäckvall group reported reduced flavin $\mathbf{2 3}$ for heteroatom oxidation mediated by the corresponding C4a-hydroperoxide intermediate (Scheme 17). ${ }^{55}$ This oxidation of $\mathrm{N}$-methylmorpholine was also applied in catalytic regeneration of $\mathrm{OsO}_{4}$ for olefin dihydroxylation. ${ }^{56}$ The higher activity of catalyst 23 compared to N5-substituted isoalloxazines in heteroatom oxidations with hydrogen peroxide was subsequently studied. ${ }^{57}$ The C4a-hydroperoxide from $\mathbf{2 3}$ was also successfully applied in aldehyde oxidations. ${ }^{58}$ Analogous N1,N5-disub- 
stituted alloxazinium salts were additionally identified as efficient catalysts in cyclobutane ring-opening reactions, ${ }^{59}$ in oxidative aromatizations, ${ }^{60}$ and in combination with iodine in aerobic oxidation reactions. ${ }^{61}$

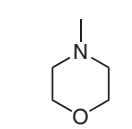

8 examples
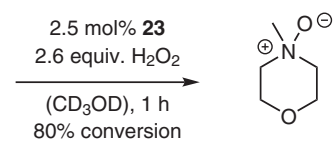

Scheme $\mathbf{1 7}$ Flavin $\mathbf{2 3}$ was found to be a highly efficient catalyst for heteroatom oxidation with hydrogen peroxide

In nature, replacing the nitrogen at the N5-position with a carbon atom is frequently observed and the corresponding deazaflavins are also part of relevant biological molecules (such as cofactors $\mathrm{F}_{0}$ and $\mathrm{F}_{420}$ ). ${ }^{62}$ The reactivity differences of molecular deazaflavins as well as their photophysical properties have been thoroughly studied..$^{63}$ They have also been applied as catalysts in [2+2]-photocycloadditions. ${ }^{64}$ In 2020, König, Cibulka, Kutta, and co-workers reported deazaflavin $\mathbf{2 4}$, which was successfully applied in one-electron reductions under irradiation resulting in dehalogenation of aryl halide substrates (Scheme 18A). ${ }^{65}$ These results are remarkable since their benchmark substrate 4-bromoanisole is very resistant towards reduction: $E_{\mathrm{red}}=-2.75 \mathrm{~V}$ (vs. SCE). In a very detailed spectro-electrochemical study, it was shown that the active catalyst species is the photoexcited semiquinone $\mathbf{2 5}^{*}$ (Scheme 18B), which is a very strong reductant $E^{*}=-3.3 \mathrm{~V}$ (vs. SCE). Semiquinone $\mathbf{2 5}$ itself is generated from the oxidized deazaflavin 24 upon photoexcitation and one-electron reduction with the sacrificial reductant $N, N$-diisopropylethylamine (DIPEA). Therefore, the mechanism of action is a consecutive photoinduced electron transfer (conPET). ${ }^{66}$
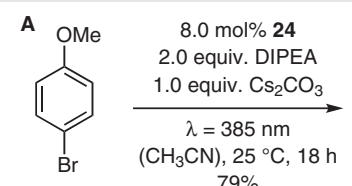

$79 \%$
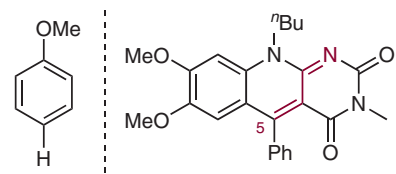

24

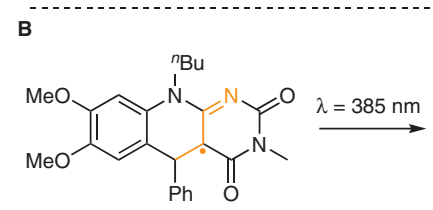

25

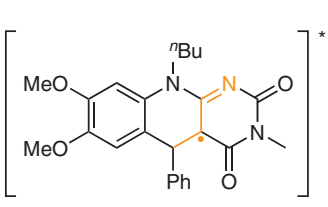

$25^{\star}$

$E\left(24 / 25^{\star}\right)=-3.3 \mathrm{~V}($ vs. SCE $)$
Scheme 18 Deazaflavins as catalysts in one-electron reduction upon photoirradiation. (A) Catalyst $\mathbf{2 4}$ was used as pre-catalyst in dehalogenation of aryl halide substrates using DIPEA as terminal reductant. (B) The photoexcited flavin semiquinone $25^{*}$ was identified as the active catalyst species.

\section{C6-C9-Modification}

Alterations at aromatic positions also profoundly affect the reactivity of flavin catalysts. In general, most flavin catalysts are either unsubstituted in positions C6-C9 or they are dimethylated in positions $\mathrm{C} 7$ and $\mathrm{C} 8$, depending on whether they are synthesized entirely or derived from (-)-riboflavin. Neither of these cases will be discussed here in detail since these alterations are of synthetic origin and not intended to change the reactivity of the catalyst. There are, however, systematic studies that link the introduction of electron-donating or electron-withdrawing groups to the C7- and C8-positions to the redox potential of the resulting flavin species. In this context, Rotello, Cooke, and co-workers reported that the reduction potential $E_{1 / 2}=-0.83 \mathrm{~V}$ (vs. SCE) of unsubstituted flavin $\mathbf{2 6}$ was significantly lowered by $-0.15 \mathrm{~V}$ through two additional methoxy groups in flavin $\mathbf{2 7}$ while being raised by $+0.16 \mathrm{~V}$ in dichloro derivative $\mathbf{2 8}$ (Figure 6). ${ }^{67}$ Throughout the previous examples, this effect has been used by $\mathrm{C} 7$-substitution with a $\mathrm{CF}_{3}$ group in order to increase electrophilicity and oxidation strength.<smiles>COc1cc2c(cc1OC)N(CC(C)C)C1C(=O)NC(=O)N(C)C1=NC2=O</smiles>

27

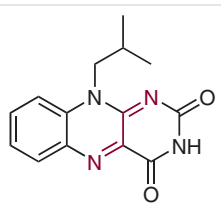

-0.83 V vs. SCE

26

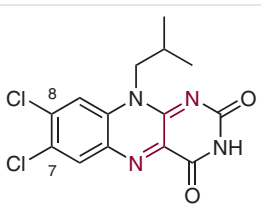

-0.67 V vs. SCE

28
Figure 6 Representative examples for the modification of redox potentials by substituents in the $\mathrm{C7}$ - and C8-positions. All values for redox potentials were converted from the original data (vs. ferrocene) into SCE using the reported method. ${ }^{68}$

However, not all substitutions at the C6-C9-positions are intended to engender changes to the redox potential. In 2016, Glusac and co-workers reported C9-iodoflavin 29 which benefits from a drastically faster intersystem crossing (ISC) to the triplet state after photoexcitation (Figure 7A). ${ }^{69}$ They demonstrated that this heavy atom effect made $\mathbf{2 9}$ a more active catalyst for the oxidation of benzyl alcohol to benzaldehyde when compared to the unsubstituted analogue. Similar observations were made by Zhao, Guo, and co-workers who reported the C7,C8-dibrominated flavin 30, again with the intention to benefit from the heavy atom effect (Figure 7B). ${ }^{70}$ They showed that the superior catalytic
A<smiles>CCn1c2nc(=O)n(C)c(=O)c-2nc2cc(C)c(C)c(I)c21</smiles>

29
B<smiles>[14CH3]n1c2nc(=O)[nH]c(=O)c-2nc2cc(Br)c(Br)cc21</smiles>

30
Figure 7 Designed flavin catalysts with iodo (A) and bromo (B) substitution, which both benefit from the heavy atom effect 
activity of $\mathbf{3 0}$ in $\mathrm{O}_{2}$-sensitization and thioether oxidation is a direct result of the increased rate of intersystem crossing.

Yoneda and co-workers showed that C6-functionalization with a carboxylic acid results in flavin derivatives that form stable semiquinone radicals 31 (Figure $8 \mathrm{~A}$ ). ${ }^{71}$ They fully characterized the latter and then apply these flavins as catalysts in the sulfoxidation of thioethers. Dimerized flavin 32 is a special case of C7,C8-modification and additionally contains a binding site for Lewis acids (Figure 8B). ${ }^{72}$ This flavin served as ligand for various metal precursors and was found to be active in oxidation of $\alpha$-hydroxycarboxylic acids to the corresponding $\alpha$-keto acids. The C7- and C8-positions have also been used to include the isoalloxazine in a crown ether motif with high affinity for potassium cations. ${ }^{73}$ When irradiated, these catalysts showed high reactivity in the oxidation of amino acid potassium salts.

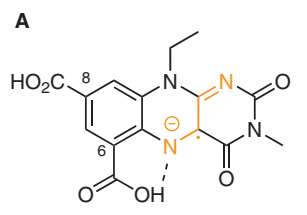

31

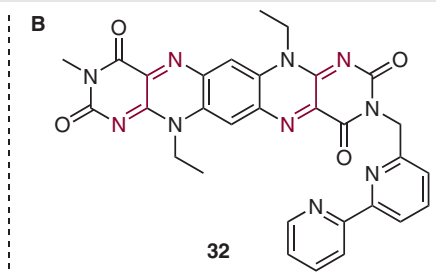

rivatives (Scheme 19B). Using (-)-riboflavin resulted in unselective substrate decomposition.

\section{N10-Modification}

In all isoalloxazines discussed here, the N10-position is attached to a carbon atom. In naturally occurring (-)-riboflavin, a ribityl substituent is attached to this position and all common variations of this sugar such as acetylation, methylation, or acetal formation will not be discussed in detail here. These alterations are not intended to change the reactivity of the flavin but rather to block the potentially interfering hydroxy groups. As an exception, the tetra-octadecanoyl functionalization of (-)-riboflavin significantly changed the properties and resulted in flavin gelation upon sonification. ${ }^{75}$ These gels have been applied in the hydrazine-mediated aerobic reduction of olefinic substrates. On the other hand, when synthesizing flavins in the laboratory, common N10-substituents include alkyl chains or aryl groups, which again will only be discussed if they serve a purpose beyond changing solubility.

An intriguing alteration of the N10-position was reported by Murahashi, Imada, and Ono in 2002 in the context of enantioselective Baeyer-Villiger oxidations. ${ }^{76}$ They showed that enantiopure trans-diaminocyclohexane (DACH) served as a suitable chiral source in order to completely control the planar chirality of bisflavinium salt 34. Both isoalloxazine cores are in a stacked arrangement and cannot rotate around the $\mathrm{N} 10-\mathrm{C}_{\mathrm{DACH}}$ single bond, resulting in stable stereoisomers. Additionally, each of the isoalloxazines serves as a steric shield for the opposite one, which leads to an efficient facial selectivity regarding the approach of substrates and reagents. Bisflavinium salt $\mathbf{3 4}$ was applied in the oxidation of cyclobutanones and achieved lactone formation with 63\% ee (Scheme 20).

A
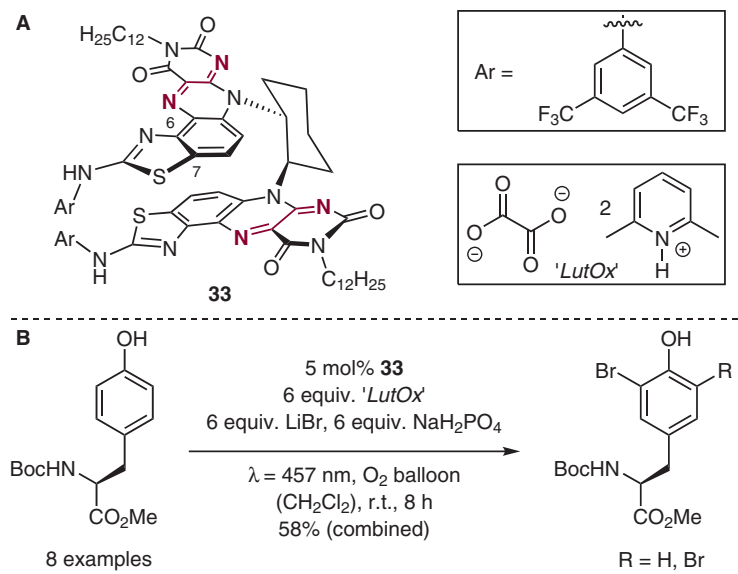

Scheme 19 Benzothiazole flavins including bisflavin $\mathbf{3 3}$ (A) are readily reduced by 2,6-lutidinium oxalate 'LutOx' and are competent catalysts for the biomimetic bromination of tyrosine and flavone derivatives (B)

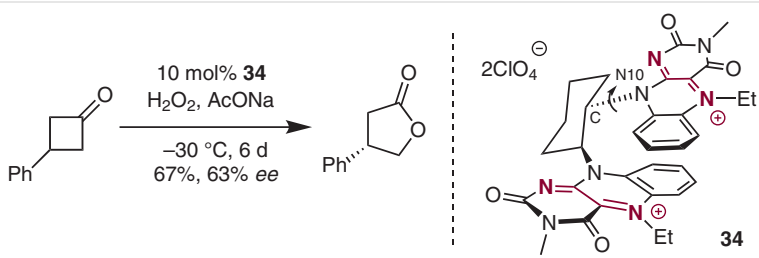

Scheme $20 \quad \mathrm{~A} \mathrm{C}_{2}$-symmetric stacked bisflavinium catalyst $\mathbf{3 4}$ and its application in enantioselective Baeyer-Villiger oxidation. Rotation around the $\mathrm{N} 10-\mathrm{C}_{\mathrm{DACH}}$ single bond (highlighted by an arrow) is hindered, leading to a stable planar chiral catalyst stereoisomer.

A similar concept was demonstrated by the Cibulka group who reported a strategy to install an aryl shield blocking one site of the isoalloxazine catalyst $35 .{ }^{77}$ Here, the planar chiral enantiomers were separated by preparative HPLC on a chiral stationary phase and again, hindered rotation around the $\mathrm{N} 10-\mathrm{C}_{\mathrm{Ar}}$ bond led to stable catalyst enantiomers that did not racemize. Flavinium salt $\mathbf{3 5}$ was ap- 
plied in the enantioselective oxidation of thioethers and a variety of modified and improved versions of this catalyst class was also explored (Scheme 21A). ${ }^{78}$ In a different approach which also relied on planar chirality, the Shinkai group developed flavinium catalyst $\mathbf{3 6}$ which is bridged between the N3- and N10-positions. ${ }^{79}$ This catalyst was also found to be stable towards racemization and was applied in thioether oxidation with enantioselectivities of up to $65 \%$ ee (Scheme 21B).
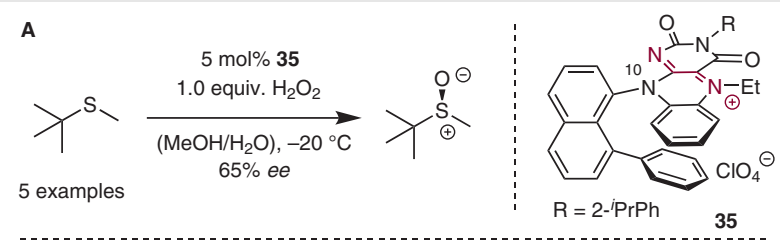

B<smiles>CSc1ccc(C)cc1</smiles>

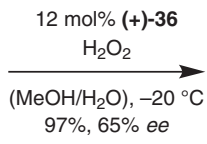
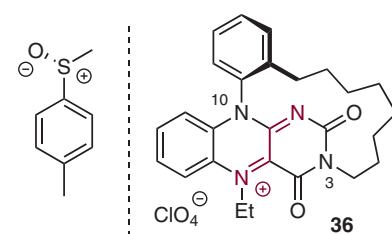

Scheme 21 The N10-modification of flavinium salts was used in order to generate planar chiral flavin catalysts. This was either achieved by stacking with an aromatic substituent (A) or by connecting the N3- and N10-positions by an alkyl chain of suitable length (B). An arbitrary enantiomer of $\mathbf{3 6}$ is drawn here in order to illustrate the planar chirality. The Shinkai group used enantiomerically pure catalyst with positive sign of optical rotation.

Apart from chiral modifications, the N10-position was used by the König group in order to obtain flavin catalyst 37 with a thiourea functionality. ${ }^{80}$ This catalyst was shown to exhibit superior properties in the oxidation of 4-methoxybenzyl alcohol and an electron-mediating effect of the thiourea was identified (Scheme 22).

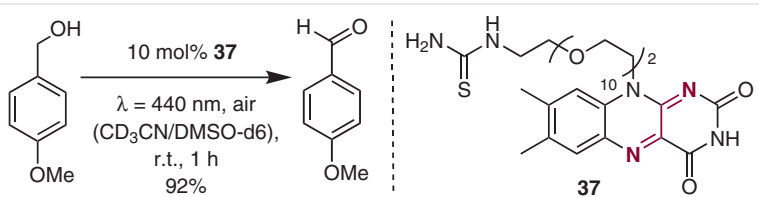

Scheme 22 Application of thiourea-modified flavin catalyst $\mathbf{3 7}$ in the oxidation of benzylic alcohol upon irradiation

The same catalytic reaction was also studied with flavin 38, which is substituted with a 2,6-dimethylphenyl group in the N10-position (Scheme 23). Gschwind, König, Cibulka, and co-workers showed that this increase in steric bulk on both sides of the isoalloxazine core resulted in a significantly decreased level of flavin aggregation. ${ }^{81}$ Flavin 38 was found to be highly catalytically active, exceeding efficiency of (-)-riboflavin in oxidation of benzylic alcohol by nearly one order of magnitude (quantum yield of the transformation).

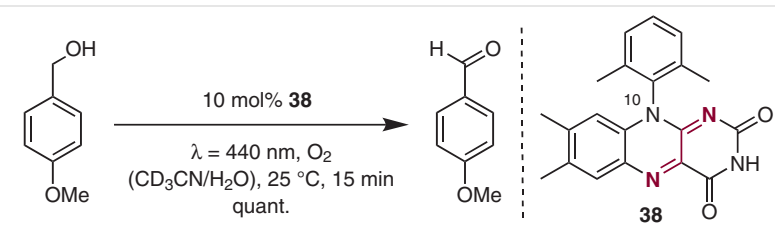

Scheme 23 The N10-modification with a 2,6-dimethylphenyl substituent results in non-aggregating flavin catalysts, which are highly efficient in oxidations upon irradiation

The N10-position has also been used to bring a second catalytically active site in close proximity to the isoalloxazine core. Imada, Arakawa, and co-workers achieved dual enamine catalysis with designed flavin 39, which contains a secondary amine unit connected to the isoalloxazine core with a proline linker. ${ }^{82}$ Catalyst 39 was applied in the $\alpha$-functionalization of aliphatic aldehydes with TEMPO (Scheme 24). The efficiency of the designed flavin compared to unmodified analogues or (-)-riboflavin was rationalized by a significant increase in reaction quantum yield of up to $\Phi=0.80$ with flavin 39 .

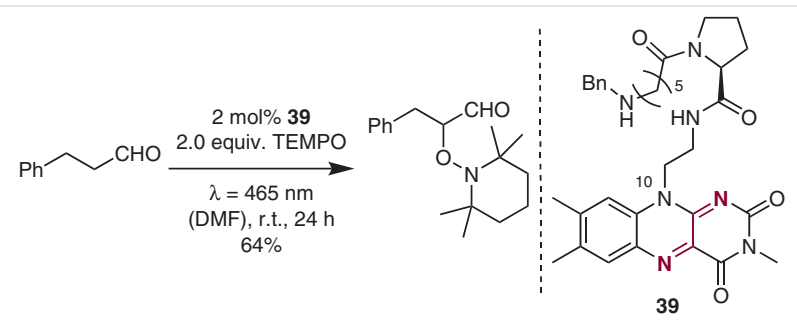

Scheme 24 A designed flavin with an additional secondary amino group was found to be well-suited for the $\alpha$-functionalization of aliphatic aldehydes by dual enamine catalysis.

\section{Conclusion}

In summary, the last decades of research on modifying molecular flavins have already yielded a significant variety of catalysts with improved reactivity or selectivity for specific applications. Initially, most transformations were inspired by fundamental studies with flavoenzyme model compounds and often guided by proof-of-concept rather than synthetic utility. This has changed significantly and the catalytic ability of flavins to use molecular oxygen from air as a green oxidant might just serve as one example of how the field contributes to sustainable methods in organic synthesis. A second example is the successful use of flavins in photocatalytic processes, which also is an important contemporary research area. Within the last few years, modifications of molecular flavins have been increasingly geared towards finding solutions for specific desired synthetic transformations besides the classical set of known reactions with (-)-riboflavin. This is a very exciting trend and a promising point in flavin catalysis research. A quick look at the incredibly diverse flavoenzyme reactivity encourages 
the anticipation of a growing variety of new designed molecular flavins for relevant synthetic challenges in the upcoming years.

\section{Conflict of Interest}

The authors declare no conflict of interest.

\section{Funding Information}

The Fonds der Chemischen Industrie (FCI, Ph.D. Fellowship to A.W. and Liebig Fellowship to G.S.) is gratefully acknowledged. Our group is supported by the Technische Universität München through the Junior Fellow Programme.

\section{Acknowledgment}

G.S. is very grateful to Prof. T. Bach for his continuous support.

\section{References}

(1) The human flavoproteome as an example: Lienhart, W.-D.; Gudipati, V.; Macheroux, P. Arch. Biochem. Biophys. 2013, 535, 150.

(2) (a) Neims, A. H.; Hellerman, L. Annu. Rev. Biochem. 1970, 39, 867. (b) Fraaije, M. W.; Mattevi, A. Trends Biochem. Sci. 2000, 25, 126. (c) Bornemann, S. Nat. Prod. Rep. 2002, 19, 761. (d) Mansoorabadi, S. O.; Thibodeaux, C. J.; Liu, H.-w. J. Org. Chem. 2007, 72, 6329. (e) Toogood, H. S.; Gardiner, J. M.; Scrutton, N. S. ChemCatChem 2010, 2, 892. (f) Walsh, C. T.; Wencewicz, T. A. Nat. Prod. Rep. 2013, 30, 175.

(3) Starbird, C. A.; Maklashina, E.; Cecchini, G.; Iverson, T. Flavoenzymes: Covalent versus Noncovalent in eLS [Online], John Wiley \& Sons September 14, 2015.

(4) Romero, E.; Gómez Castellanos, J. R.; Gadda, G.; Fraaije, M. W.; Mattevi, A. Chem. Rev. 2018, 118, 1742.

(5) Representative recent examples for the comparison between flavoenzyme and isolated cofactor: (a) Clayman, P. D.; Hyster, T. K. J. Am. Chem. Soc. 2020, 142, 15673. (b) Huang, X.; Wang, B.; Wang, Y.; Jiang, G.; Feng, J.; Zhao, H. Nature 2020, 584, 69. (c) Sandoval, B. A.; Clayman, P. D.; Oblinsky, D. G.; Oh, S.; Nakano, Y.; Bird, M.; Scholes, G. D.; Hyster, T. K.J. Am. Chem. Soc. 2021, 143, 1735.

(6) (a) Imada, Y.; Naota, T. Chem. Rec. 2007, 7, 354. (b) Iida, H.; Imada, Y.; Murahashi, S. I. Org. Biomol. Chem. 2015, 13, 7599. (c) Cibulka, R. Eur. J. Org. Chem. 2015, 915.

(7) (a) Sideri, I. K.; Voutyritsa, E.; Kokotos, C. G. Org. Biomol. Chem. 2018, 16, 4596. (b) König, B.; Kümmel, S.; Svobodová, E.; Cibulka, R. Phys. Sci. Rev. 2018, 3, 20170168.

(8) Li, W.-S.; Zhang, N.; Sayre, L. M. Tetrahedron 2001, 57, 4507.

(9) Marsh, B. J.; Carbery, D. R. Tetrahedron Lett. 2010, 51, 2362.

(10) Zelenka, J.; Hartman, T.; Klímová, K.; Hampl, F.; Cibulka, R. ChemCatChem 2014, 6, 2843.

(11) Murray, A. T.; Matton, P.; Fairhurst, N. W. G.; John, M. P.; Carbery, D. R. Org. Lett. 2012, 14, 3656.

(12) Sakai, T.; Watanabe, M.; Ohkado, R.; Arakawa, Y.; Imada, Y.; Iida, H. ChemSusChem 2019, 12, 1640.
(13) (a) Žurek, J.; Cibulka, R.; Dvořáková, H.; Svoboda, J. Tetrahedron Lett. 2010, 51, 1083. (b) Žurek, J.; Svobodová, E.; Šturala, J.; Dvořáková, H.; Svoboda, J.; Cibulka, R. Tetrahedron: Asymmetry 2017, 28, 1780.

(14) Poudel, P. P.; Arimitsu, K.; Yamamoto, K. Chem. Commun. 2016, $52,4163$.

(15) Marsh, B. J.; Heath, E. L.; Carbery, D. R. Chem. Commun. 2011, 47, 280.

(16) (a) Zhu, C.; Li, Q.; Pu, L.; Tan, Z.; Guo, K.; Ying, H.; Ouyang, P. ACS Catal. 2016, 6, 4989. (b) Tan, Z.; Zhu, C.; Fu, J.; Zhang, X.; Li, M.; Zhuang, W.; Ying, H. Angew. Chem. Int. Ed. 2018, 57, 16464.

(17) (a) Ishikawa, T.; Kimura, M.; Kumoi, T.; Iida, H. ACS Catal. 2017, 7, 4986. (b) Jiang, X.; Zhao, Z.; Shen, Z.; Chen, K.; Fang, L.; Yu, C. Eur. J. Org. Chem. 2020, 3889.

(18) Thapa, P.; Hazoor, S.; Chouhan, B.; Vuong, T. T.; Foss, F. W. Jr. J. Org. Chem. 2020, 85, 9096.

(19) März, M.; Babor, M.; Cibulka, R. Eur.J. Org. Chem. 2019, 3264.

(20) Zelenka, J.; Svobodová, E.; Tarábek, J.; Hoskovcová, I.; Boguschová, V.; Bailly, S.; Sikorski, M.; Roithová, J.; Cibulka, R. Org. Lett. 2019, 21, 114.

(21) Tolba, A. H.; Vávra, F.; Chudoba, J.; Cibulka, R. Eur. J. Org. Chem. 2020, 1579.

(22) Zelenka, J.; Cibulka, R.; Roithová, J. Angew. Chem. Int. Ed. 2019, $58,15412$.

(23) Mojr, V.; Svobodová, E.; Straková, K.; Neveselý, T.; Chudoba, J.; Dvořáková, H.; Cibulka, R. Chem. Commun. 2015, 51, 12036.

(24) Špačková, J.; Svobodová, E.; Hartman, T.; Stibor, I.; Kopecká, J.; Cibulková, J.; Chudoba, J.; Cibulka, R. ChemCatChem 2017, 9, 1177.

(25) Jirásek, M.; Straková, K.; Neveselý, T.; Svobodová, E.; Rottnerová, Z.; Cibulka, R. Eur. J. Org. Chem. 2017, 2139.

(26) (a) Insińska-Rak, M.; Sikorska, E.; Bourdelande, J. L.; Khmelinskii, I. V.; Prukała, W.; Dobek, K.; Karolczak, J.; Machado, I. F.; Ferreira, L. F. V.; Dulewicz, E.; Komasa, A.; Worrall, D. R.; Kubicki, M.; Sikorski, M.J. Photochem. Photobiol. A 2007, 186, 14. (b) Wolnicka-Glubisz, A.; Pawlak, A.; InsinskaRak, M.; Zadlo, A. J. Photochem. Photobiol. B 2020, 205, 111820.

(27) Tan, S. L. J.; Novianti, M. L.; Webster, R. D. J. Phys. Chem. B 2015, 119, 14053.

(28) Cibulka, R.; Vasold, R.; König, B. Chem. Eur. J. 2004, 10, 6223.

(29) Metternich, J. B.; Sagebiel, S.; Lückener, A.; Lamping, S.; Ravoo, B. J.; Gilmour, R. Chem. Eur. J. 2018, 24, 4228.

(30) Imada, Y.; Osaki, M.; Noguchi, M.; Maeda, T.; Fujiki, M.; Kawamorita, S.; Komiya, N.; Naota, T. ChemCatChem 2015, 7, 99.

(31) Kurfiřt, M.; Špačková, J.; Svobodová, E.; Cibulka, R. Monatsh. Chem. 2018, 149, 863.

(32) Arakawa, Y.; Yamanomoto, K.; Kita, H.; Minagawa, K.; Tanaka, M.; Haraguchi, N.; Itsuno, S.; Imada, Y. Chem. Sci. 2017, 8, 5468.

(33) Kemal, C.; Bruice, T. C. Proc. Natl. Acad. Sci. U.S.A. 1976, 73, 995.

(34) Kemal, C.; Chan, T. W.; Bruice, T. C. Proc. Natl. Acad. Sci. U.S.A. 1977, 74, 405.

(35) (a) Arakawa, Y.; Oonishi, T.; Kohda, T.; Minagawa, K.; Imada, Y. ChemSusChem 2016, 9, 2769. (b) Sakai, T.; Kumoi, T.; Ishikawa, T.; Nitta, T.; Iida, H. Org. Biomol. Chem. 2018, 16, 3999.

(36) Ménová, P.; Eigner, V.; Čejka, J.; Dvořáková, H.; Šanda, M.; Cibulka, R. J. Mol. Struct. 2011, 1004, 178.

(37) Oonishi, T.; Kawahara, T.; Arakawa, Y.; Minagawa, K.; Imada, Y. Eur. J. Org. Chem. 2019, 1791.

(38) Sichula, V.; Kucheryavy, P.; Khatmullin, R.; Hu, Y.; Mirzakulova, E.; Vyas, S.; Manzer, S. F.; Hadad, C. M.; Glusac, K. D. J. Phys. Chem. A 2010, 114, 12138.

(39) Ball, S.; Bruice, T. C. J. Am. Chem. Soc. 1980, 102, 6498. 
(40) Murahashi, S.-I.; Oda, T.; Masui, Y. J. Am. Chem. Soc. 1989, 111, 5002.

(41) (a) Imada, Y.; Ohno, T.; Naota, T. Tetrahedron Lett. 2007, 48, 937. (b) Mojr, V.; Herzig, V.; Buděšínský, M.; Cibulka, R.; Kraus, T. Chem. Commun. 2010, 46, 7599. (c) Ménová, P.; Cibulka, R. J. Mol. Catal. A: Chem. 2012, 363-364, 362. (d) Hartman, T.; Herzig, V.; Buděšínský, M.; Jindřich, J.; Cibulka, R.; Kraus, T. Tetrahedron: Asymmetry 2012, 23, 1571. (e) Imada, Y.; Kitagawa, T.; Iwata, S.; Komiya, N.; Naota, T. Tetrahedron 2014, 70, 495. (f) Iida, H.; Ishikawa, T.; Nomura, K.; Murahashi, S.-I. Tetrahedron Lett. 2016, 57, 4488.

(42) Baxová, L.; Cibulka, R.; Hampl, F. J. Mol. Catal. A: Chem. 2007, 277, 53.

(43) Iida, H.; Iwahana, S.; Mizoguchi, T.; Yashima, E. J. Am. Chem. Soc. 2012, 134, 15103

(44) Mazzini, C.; Lebreton, J.; Furstoss, R. J. Org. Chem. 1996, $61,8$.

(45) Imada, Y.; Iida, H.; Ono, S.; Murahashi, S.-I. J. Am. Chem. Soc. 2003, 125, 2868.

(46) (a) Imada, Y.; Iida, H.; Ono, S.; Masui, Y.; Murahashi, S.-I. Chem. Asian J. 2006, 1, 136. (b) Imada, Y.; Tonomura, I.; Komiya, N.; Naota, T. Synlett 2013, 24, 1679.

(47) Murahashi, S.-I.; Zhang, D.; Iida, H.; Miyawaki, T.; Uenaka, M.; Murano, K.; Meguro, K. Chem. Commun. 2014, 50, 10295.

(48) Imada, Y.; Kitagawa, T.; Wang, H.-K.; Komiya, N.; Naota, T. Tetrahedron Lett. 2013, 54, 621.

(49) Imada, Y.; Iida, H.; Naota, T. J. Am. Chem. Soc. 2005, 127, 14544.

(50) (a) Smit, C.; Fraaije, M. W.; Minnaard, A. J.J. Org. Chem. 2008, 73, 9482. (b) Imada, Y.; Iida, H.; Kitagawa, T.; Naota, T. Chem. Eur. J. 2011, 17, 5908.

(51) Imada, Y.; Iida, H.; Murahashi, S. I.; Naota, T. Angew. Chem. Int. Ed. 2005, 44, 1704.

(52) Iida, H.; Demizu, R.; Ohkado, R. J. Org. Chem. 2018, 83, 12291.

(53) Mirzakulova, E.; Khatmullin, R.; Walpita, J.; Corrigan, T.; VargasBarbosa, N. M.; Vyas, S.; Oottikkal, S.; Manzer, S. F.; Hadad, C. M.; Glusac, K. D. Nat. Chem. 2012, 4, 794.

(54) Pouy, M. J.; Milczek, E. M.; Figg, T. M.; Otten, B. M.; Prince, B. M.; Gunnoe, T. B.; Cundari, T. R.; Groves, J. T. J. Am. Chem. Soc. 2012, $134,12920$.

(55) (a) Bergstad, K.; Bäckvall, J.-E. J. Org. Chem. 1998, 63, 6650. (b) Lindén, A. A.; Krüger, L.; Bäckvall, J.-E. J. Org. Chem. 2003, 68, 5890. (c) Lindén, A. A.; Hermanns, N.; Ott, S.; Krüger, L.; Bäckvall, J.-E. Chem. Eur. J. 2005, 11, 112. (d) Lindén, A. A.; Johansson, M.; Hermanns, N.; Bäckvall, J.-E. J. Org. Chem. 2006, $71,3849$.

(56) (a) Bergstad, K.; Jonsson, S. Y.; Bäckvall, J.-E. J. Am. Chem. Soc. 1999, 121, 10424. (b) Jonsson, S. Y.; Adolfsson, H.; Bäckvall, J.-E. Org. Lett. 2001, 3, 3463.

(57) Minidis, A. B. E.; Bäckvall, J.-E. Chem. Eur. J. 2001, 7, 297.

(58) (a) Chen, S.; Hossain, M. S.; Foss, F. W. Org. Lett. 2012, 14, 2806. (b) Chen, S.; Foss, F. W. Org. Lett. 2012, 14, 5150.

(59) Hartman, T.; Cibulka, R. Org. Lett. 2016, 18, 3710.

(60) Chen, S.; Hossain, M. S.; Foss, F. W. ACS Sustainable Chem. Eng. 2013, 1, 1045.

(61) (a) Ohkado, R.; Ishikawa, T.; Iida, H. Green Chem. 2018, 20, 984. (b) Tanimoto, K.; Ohkado, R.; Iida, H. J. Org. Chem. 2019, 84, 14980. (c) Okai, H.; Tanimoto, K.; Ohkado, R.; Iida, H. Org. Lett. 2020, 22, 8002.
(62) Greening, C.; Ahmed, F. H.; Mohamed, A. E.; Lee, B. M.; Pandey, G.; Warden, A. C.; Scott, C.; Oakeshott, J. G.; Taylor, M. C.; Jackson, C. J. Microbiol. Mol. Biol. Rev. 2016, 80, 451.

(63) (a) Hemmerich, P.; Massey, V. FEBS Lett. 1977, 84, 5. (b) Link, P. A. J.; Plas, H. C. V. D.; Müller, F. Photochem. Photobiol. 1987, 45, 557. (c) Yanada, R.; Yoneda, Y.; Yazaki, M.; Mimura, N.; Taga, T.; Yoneda, F.; Yanada, K. Tetrahedron: Asymmetry 1997, 8, 2319.

(64) Mojr, V.; Pitrová, G.; Straková, K.; Prukała, D.; Brazevic, S.; Svobodová, E.; Hoskovcová, I.; Burdziński, G.; Slanina, T.; Sikorski, M.; Cibulka, R. ChemCatChem 2018, 10, 849.

(65) Graml, A.; Neveselý, T.; Kutta, R. J.; Cibulka, R.; König, B. Nat. Commun. 2020, 11, 3174.

(66) Ghosh, I.; Ghosh, T.; Bardagi, J. I.; König, B. Science 2014, 346, 725.

(67) Legrand, Y.-M.; Gray, M.; Cooke, G.; Rotello, V. M. J. Am. Chem. Soc. 2003, 125, 15789.

(68) Pavlishchuk, V. V.; Addison, A. W. Inorg. Chim. Acta 2000, 298, 97.

(69) Korvinson, K. A.; Hargenrader, G. N.; Stevanovic, J.; Xie, Y.; Joseph, J.; Maslak, V.; Hadad, C. M.; Glusac, K. D. J. Phys. Chem. A 2016, $120,7294$.

(70) Dang, C.; Zhu, L.; Guo, H.; Xia, H.; Zhao, J.; Dick, B. ACS Sustainable Chem. Eng. 2018, 6, 15254.

(71) Akiyama, T.; Simeno, F.; Murakami, M.; Yoneda, F. J. Am. Chem. Soc. 1992, 114, 6613.

(72) (a) Yano, Y.; Mitsui, K.; Ohsawa, Y.; Kobayashi, T.; Nabeshima, T. J. Chem. Soc., Chem. Commun. 1993, 1719. (b) Ohshiro, H.; Mitsui, K.; Ando, N.; Ohsawa, Y.; Koinuma, W.; Takahashi, H.; Kondo, S.-i.; Nabeshima, T.; Yano, Y. J. Am. Chem. Soc. 2001, 123, 2478.

(73) (a) Shinkai, S.; Nakao, H.; Ueda, K.; Manabe, O. Tetrahedron Lett. 1984, 25, 5295. (b) Shinkai, S.; Ishikawa, Y.; Shinkai, H.; Tsuno, T.; Makishima, H.; Ueda, K.; Manabe, O. J. Am. Chem. Soc. 1984, 106,1801

(74) Walter, A.; Storch, G. Angew. Chem. Int. Ed. 2020, 59, 22505.

(75) Kawamorita, S.; Fujiki, M.; Li, Z.; Kitagawa, T.; Imada, Y.; Naota, T. ChemCatChem 2019, 11, 878.

(76) Murahashi, S.-I.; Ono, S.; Imada, Y. Angew. Chem. Int. Ed. 2002, $41,2366$.

(77) Jurok, R.; Cibulka, R.; Dvořáková, H.; Hampl, F.; Hodačová, J. Eur. J. Org. Chem. 2010, 5217.

(78) Jurok, R.; Hodačová, J.; Eigner, V.; Dvořáková, H.; Setnička, V.; Cibulka, R. Eur. J. Org. Chem. 2013, 7724.

(79) (a) Shinkai, S.; Yamaguchi, T.; Kawase, A.; Kitamura, A.; Manabe, O. J. Chem. Soc., Chem. Commun. 1987, 1506. (b) Shinkai, S.; Yamaguchi, T.; Manabe, O.; Toda, F. J. Chem. Soc., Chem. Commun. 1988, 1399.

(80) Svoboda, J.; Schmaderer, H.; König, B. Chem. Eur. J. 2008, 14, 1854.

(81) Dad’ová, J.; Kümmel, S.; Feldmeier, C.; Cibulková, J.; Pažout, R.; Maixner, J.; Gschwind, R. M.; König, B.; Cibulka, R. Chem. Eur. J. 2013, 19, 1066.

(82) Tagami, T.; Arakawa, Y.; Minagawa, K.; Imada, Y. Org. Lett. 2019, $21,6978$. 